\title{
ANÁLISE ESTRUTURAL APÓS CADA ETAPA DE PROCESSAMENTO DE CHAPAS DE AÇO BIFÁSICO GALVANIZADO*
}

\author{
Daniel de Carvalho Silva ${ }^{1}$ \\ Andersan dos Santos Paula ${ }^{2}$ \\ Rodrigo Rocha Meira ${ }^{3}$ \\ Mônica Aline Magalhães Gurge/ ${ }^{4}$
}

\section{Resumo}

O presente trabalho estuda a evolução microestrutural e mecânica ao longo do processo de produção de um aço baixo carbono com micro adição de molibdênio, destinado a produção de chapas de aço dual phase galvanizadas. Para realização do estudo foi feita a caracterização microestrutural e mecânica ao longo do processo produtivo de amostras (placa, chapa laminada a quente, chapa laminada a frio "full hard", e galvanizada) deste aço via microscopia ótica e eletrônica de varredura das amostras, avaliação da dureza via microdurômetro, do comportamento mecânico via ensaio de tração, este último somente nas amostras de chapa laminada a quente e galvanizada. Os resultados obtidos revelaram um aumento significativo na resistência mecânica do material conjugada uma alta ductilidade, devido principalmente ao refino de grão e a formação de dispersão de martensita.

Palavras-chave: Aço bifásico; Propriedade mecânica; Caracterização microestrutural.

\section{STRUCTURAL ANALYSIS AFTER EACH STEP PROCESSING OF DUAL PHASE GALVANIZED STEEL SHEET}

\begin{abstract}
The present work study the microstructural and mechanical evolution during each step for low carbon steel with molybdenum microaddition galvannead dual phase sheet production. Hot rolled, cold rolled and galvannead samples (with same chemical composition) were collect in order to observe theirs microstructural and mechanical properties. The characterizations were performed by optical microscopy, scanning electronic microscopy, microhardness and tensile tests. The results shown that a significantly increased in mechanical resistance conjugated with high ductility and formability promoted by grain size reduction and martensite dispersion.
\end{abstract}

Keywords: Dual phase steel; Mechanical properties; Microstructural characterization.

1 Engenheiro Metalurgista, Mestrando da PPGEM/UFF, Volta Redonda/RJ, Brasil

2 Engenheira Metalurgista, D.Sc., Professor Adjunta, Instituto Militar de Engenharia, Rio de Janeiro, RJ, Brasil; e orientadora credenciada da PPGEM/UFF, Volta Redonda, RJ, Brasil.

3 Engenheiro Metalurgista. M.Sc. Eng. Especialista de Desenvolvimento na CSN, Volta Redonda/RJ, Brasil.

4 Engenheira Metalurgista, M. Sc. Eng. Metalúrgica pela PPGEM/UFF, Doutoranda em Ciência dos Materiais no PGCM/ SE.4 no IME, Rio de Janeiro,/RJ, Brasil. 


\section{INTRODUÇÃO}

A indústria automobilística num esforço contínuo para desenvolver veículos mais leves, mais seguros e mais duráveis levou a indústria siderúrgica a intensificar esforços na melhoria do desempenho dos aços destinados a este segmento [1]. Surgindo assim no final da década de 1970 o primeiro desenvolvimento nesse sentido, o assim chamado aço bifásico ("Dual Phase" ou DP), que, como seu nome dá a entender, apresenta microestrutura constituída por uma matriz de ferrita poligonal macia somada a martensita dura [2]. Esses aços bifásicos surgiram como uma solução para aplicações que requeiram uma razoável ductilidade, boa conformabilidade, aliada a uma considerável resistência e boa soldabilidade [1] Esses aços apresentam uma microestrutura mais complexas do que as ferríticas ou ferrítico-perlíticas normalmente presentes nas ligas comuns de baixo $\mathrm{C}$. Devido a matriz ferrítica e ilhas dispersas de martensita, ou de acordo com o processamento a presença de bainita e perlita resultando assim em interações mais complexas entre os vários constituintes presentes, os quais, por sua vez, promove variações significativas de dureza entre si, além de apresenta uma série de características mecânicas que lhe asseguram boa conformabilidade: escoamento contínuo, ou seja, ausência do patamar de escoamento típico dos aços ferrítico-perlíticos, mesmo microligados [3].

$\mathrm{O}$ aço plano tem sido, ao longo dos anos, o principal material utilizado pela indústria automobilística para fabricação de carrocerias. O uso de chapas de aço com revestimento de zinco aumentou nos últimos anos, devido à maior durabilidade destes produtos sob corrosão. Sendo a resistência à corrosão nos dias de hoje um dos requisitos básicos dos automóveis, deixando de ser considerada como um diferencial. Os projetos desenvolvidos pelas diferentes montadoras apresentam características especiais quanto ao tipo de revestimento a ser aplicado nas diferentes peças. Sendo assim a utilização de aços bifásicos têm-se ampliado, gerando também uma demanda desse aço revestido, que alia a resistência mecânica com a resistência à corrosão promovida pela galvanização [1].

Devido a esses fatores a siderurgia vem neste contexto produzindo aços bifásicos via galvanização contínua, o que torna o controle da microestrutura muito mais crítico devido às baixas taxas de resfriamentos praticadas.

Neste trabalho objetivou-se realizar uma caracterização de um aço baixo carbono com micro adição de Molibdênio destinado a produção de chapas de aço "Dual Phase" laminadas a frio e galvanizadas, através de amostras retiradas ao longo do processo produtivo de aço, ou seja, amostras retiradas da placa, da bobina laminada a quente, da bobina "full hard" e após galvanização, onde realizou-se caracterização microestrutural via microscopia ótica e eletrônica de varredura, avaliação da dureza via microdurômetro e avaliação do comportamento mecânico via ensaio de tração, somente nas amostras de chapa laminada a quente e galvanizada.

\section{MATERIAIS E MÉTODOS}

\subsection{Material}

O material em estudo foi um aço baixo carbono com adição de molibdênio. Para o devido acompanhamento microestrutural em estudo foram retiradas amostras ao longo do processo de produção: da placa; após o processo de laminação quente (LQ); após laminação a frio (LF); e após a galvanização na planta da CSN Porto Real. A 
composição química do material está representada pelas percentagens máximas dos elementos de liga na Tabela 1.

Tabela 1. Composição química do material em estudo.

\begin{tabular}{|c|c|c|c|c|c|}
\hline \multicolumn{6}{|c|}{ Composição Quimica (\% em peso) } \\
\hline C & S & Mn & P & Si+Cr+Mo & Al \\
\hline$<0,10$ & $<0,15$ & $>1,5$ & $<0,15$ & $<0,60$ & $<0,080$ \\
\hline
\end{tabular}

\subsection{Métodos}

\subsubsection{Preparação Metalográfica e Análise Microestrutural}

De modo a obter as amostras para as análises metalográficas e de dureza foi conduzida a preparação metalográfica. Na qual após o corte, tendo o cuidado de deixar na parte a ser analisada a direção de laminação, as amostras foram decapadas com solução de ácido clorídrico para limpeza no caso da $L Q$ e $L F$ e remoção do revestimento no caso das amostras galvanizadas. As amostras foram embutidas a quente em baquelite, seguido do processo de lixamento com lixas de carbeto de silício na sequência de 150, 240, 400, 600 e 1200 Mesh, fazendo uso de água como líquido refrigerante e lubrificante. $O$ polimento foi manual, com pano de polimento e pasta de diamante nas granulometrias de 6, 3 e $1 \mu \mathrm{m}$, com lubrificação de álcool absoluto $99,3 \%$. Por fim as amostras foram atacadas com dois reagentes: o Nital e o Picral.

O Nital 3\% (3\% de ácido nítrico e $97 \%$ de álcool etílico PA), por esfregamento com algodão por 4 segundos e posterior remoção do ataque com auxílio de uma etapa de polimento com solução de alumina na granulometria de $0,05 \mu \mathrm{m}$ e lubrificação de água destilada, seguido de um re-ataque nas mesmas condições de Nital. Para a quantificação da segunda fase formada, utilizou-se o ataque com Picral $4 \%$, até que as amostras ficassem foscas. A fim de otimizar os resultados com os ataques Picral $4 \%$, a solução original foi submetida a um tratamento de envelhecimento, onde o composto de ácido pícrico diluído em etanol na concentração de $4 \%$ é adicionado pequenos pedaços de aço. As imagens foram realizadas na seção transversal associada a direção de laminação a $1 / 4$ da espessura, para um melhor tratamento estatístico foram realizadas 10 micrografias na direção de laminação (DL) e 10 na direção transversal a laminação (DT). As caracterizações microestruturais foram realizadas por meio da microscopia ótica, porém para confirmação dos resultados obtidos com o ataque Nital as amostras laminadas a frio (LF) e galvanizada foram analisadas por meio de Microscopia Eletrônica de Varredura (MEV) Carl Zeiss (modelo EVO MA 10 com filamento de tungstênio, instalado na EEIMVR/UFF, com tensão de aceleração de $22 \mathrm{kV}$ ) com detector de elétrons secundários (spot size de 550 e distância de trabalho de $9 \mathrm{~mm}$ ).

De posse das micrografias foram realizadas:

- a quantificação da fração volumétrica das amostras atacadas com Nital e Picral, com o auxílio da macro "Phase" do módulo "Materials - Pro" do programa "Image Pro Plus", sendo feito o cálculo da média e desvio padrão a partir de imagens de regiões distintas da amostra com aumento de 1000x.

- a avaliação do tamanho médio de grão (TG) pelo método do intercepto de Heyn (ou Método Linear) nas amostras: placa, LQ e galvanizada. A amostra LF não apresentou grãos definidos devido ao encruamento sofrido e por esse motivo não foi realizado a análise de tamanho de grão nela. 


\subsubsection{Ensaios Mecânicos}

Para o ensaio de dureza foi utilizado o microdurômetro Ernst Leitz do laboratório de metalografia da UFF respeitando a distância entre as indentações de pelo menos sete vezes o tamanho desta e o tempo de penetração de 20 segundos, onde realizou-se 10 medições distribuídas ao longo de um quarto da espessura da amostra, em uma linha paralela à borda, calculando a média aritmética dos valores obtidos.

Para o ensaio de tração foram retirados 5 corpos de prova na base $80 \mathrm{~mm}$ para cada direção de laminação tanto da bobina quente bem como o da bobina zincada, sendo estas direções: a de laminação (DL), a diagonal a laminação (DD) e a direção transversal a laminação (DT). O ensaio de tração foi realizado em uma máquina de tração Instron 4204 com célula de carga de 150 KN, o software utilizado para obtenção dos resultados foi o Series que com auxílio do extensômetro "clip gage" para base 80 gerou os dados de propriedades mecânicas do limite de resistência (LR), da razão elástica $(R)$ e o alongamento total até a fratura $(\Delta L)$. A velocidade de ensaio foi de 2 $\mathrm{mm} / \mathrm{min}$ até o limite de escoamento (LE) e de $10 \mathrm{~mm} / \mathrm{min}$ após o LE. Para as amostras galvanizadas os ensaios foram realizados em uma máquina de tração Instron 5582 com célula de carga de $100 \mathrm{KN}$, o software utilizado para obtenção dos resultados foi - Bluehill que através do AVE (Advanced Video Extensometer) gerou os dados de propriedades mecânicas do limite de escoamento a 0,2\% de deformação (LE 0,2\%), do limite de resistência (LR), da razão elástica $(R)$, do alongamento total até a fratura $(\Delta L)$, do coeficiente de encruamento entre 10 e $20 \%$ de deformação (n 10-20\%). Os cálculos para tensão e deformação foram com base nos conceitos de Tensão e Deformação de Engenharia. O coeficiente de anisotropia $r$ foi obtido pelo software da máquina, sendo este obtido a uma deformação de $20 \%$ (r-20\%). Através dos dados de r nas direções DL, DT e DD foi possível calcular o valor médio tendo em vista que o mesmo varia no plano da chapa, este valor médio é conhecido por coeficiente de anisotropia normal $r$.

Através dos dados de $r$ nas direções DL, DT e DD foi possível calcular também o coeficiente de anisotropia planar que indica a diferença de comportamento mecânico que o material pode apresentar no plano da chapa. A velocidade de ensaio foi de 3 $\mathrm{mm} / \mathrm{min}$ até o LE e após de $10 \mathrm{~mm} / \mathrm{min}$.

\section{RESULTADOS E DISCUSSÃO}

\subsection{Caracterização Microestrutural}

\subsubsection{Placa}

Na Figura 1 são apresentadas as micrografias das amostras da placa após ataque com Nital, em três regiões distintas, onde pode-se observar a presença da matriz ferrítica na tonalidade clara e a presença de perlita na tonalidade escura. Através da análise das micrografias foi possível constatar que a microestrutura apresentou homogeneidade ao logo de toda a seção das direções analisadas. Os grãos ferríticos e a perlita se apresentaram de forma grosseira devido ao processo de solidificação que envolve um resfriamento lento desde a temperatura de lingotamento até a temperatura ambiente 

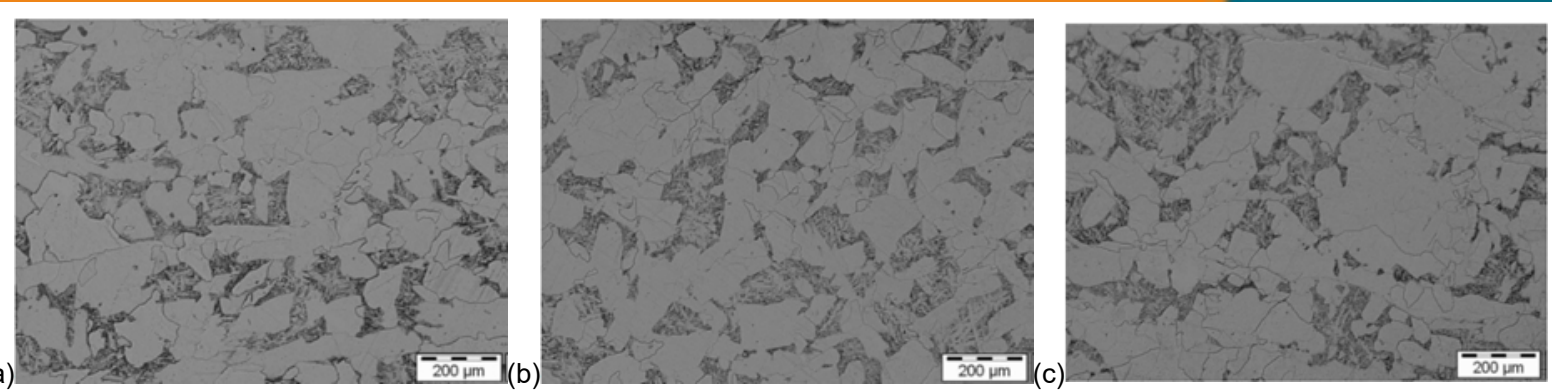

Figura 1. Micrografia das amostras a)1, b)2 e c)3 apresentando matriz ferrítica com regiões de perlita, ataque Nital, 100x.

Com base na análise microestrutural realizada, foi procedida a quantificação de fases e avaliação do tamanho de grão ferrítico presente na placa do material em estudo, onde os resultados são apresentados nas Tabelas 3 e 4.

Tabela 3. Quantificação de fase das amostras 1, 2 e 3 oriundas da placa em estudo

\begin{tabular}{|c|c|c|c|c|c|c|}
\hline Amostra & \multicolumn{2}{|c|}{1} & \multicolumn{2}{|c|}{2} & \multicolumn{2}{|c|}{3} \\
\hline \multirow{2}{*}{ Fase } & Ferrita & Perlita & Ferrita & Perlita & Ferrita & Perlita \\
\cline { 2 - 7 } & $\%$ & $\%$ & $\%$ & $\%$ & $\%$ & $\%$ \\
\hline Média & 85,47 & 14,53 & 86,67 & 13,33 & 86,40 & 13,60 \\
\hline Desvio Padrão & 1,90 & 1,90 & 0,61 & 0,61 & 1,58 & 1,58 \\
\hline
\end{tabular}

Tabela 4. Determinação do tamanho de grão ferrítico das amostras 1, 2 e 3 da placa em estudo.

\begin{tabular}{|c|c|c|c|c|c|c|}
\hline Amostra & \multicolumn{2}{|c|}{1} & \multicolumn{2}{|c|}{2} & \multicolumn{2}{|c|}{3} \\
\hline Unidade & $\mu \mathrm{m}$ & ASTM & $\mu \mathrm{m}$ & ASTM & $\mu \mathrm{m}$ & ASTM \\
\hline Média & 42,43 & 6 & 35,13 & 6 & 43,60 & 6 \\
\hline Desvio Padrão & 5,99 & 0,4 & 3,07 & 0,3 & 4,38 & 0,3 \\
\hline
\end{tabular}

\subsubsection{Laminada a quente}

Na Figura 2 são apresentas as micrografias das amostras laminadas a quente após o ataque com Nital, na direção de laminação e transversal. Pode ser observado um refino de grão se comparado com a Figura 1. Esse refino de grão está associado ao tratamento termomecânico de laminação a quente controlada que ao reduzir a espessura a uma temperatura acima de Ar3, gera encruamento dos grãos austeníticos em paralelo a sua recristalização (dinâmica e/ou estática), a qual em cada grão encruado nucleia em novos grãos livres de deformação, gerando uma microestrutura altamente refinada. Pode ser observado na Figura 2(a) um alongamento dos grãos na direção de laminação e a presença de perlita em ambas amostras.

(a)
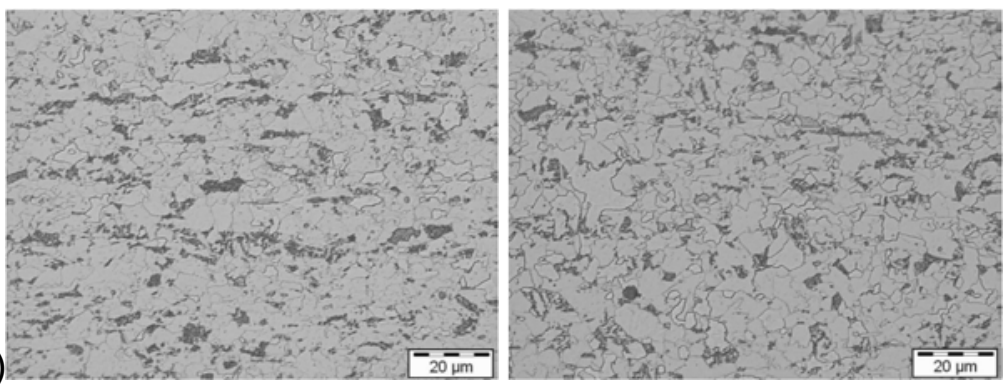

(b)

Figura 2. Micrografia das amostras Laminadas a quente a) DL, b) DT apresentando matriz ferritica com regiões de perlita, ataque Nital 3\%, aumento de 1000X. 
Com base na análise microestrutural realizada, foi procedida a quantificação de fases e avaliação do tamanho de grão ferrítico dessa condição (LQ) do material em estudo, apresentados nas Tabelas 5 e 6.

Tabela 5. Quantificação de fase das amostras laminadas a quente DL.

\begin{tabular}{|c|c|c|c|c|}
\hline \multirow{2}{*}{ Direção } & \multicolumn{2}{|c|}{ DL } & \multicolumn{2}{c|}{ DT } \\
\hline & Ferrita & Perlita & Ferrita & Perlita \\
\cline { 2 - 5 } & $\%$ & $\%$ & $\%$ & $\%$ \\
\hline Média & 87,12 & 12,88 & 87,17 & 12,83 \\
\hline Desvio Padrão & 0,97 & 0,97 & 1,14 & 1,14 \\
\hline
\end{tabular}

Tabela 6. Determinação do tamanho de grão das amostras laminadas a quente DL e DT.

\begin{tabular}{|c|c|c|c|c|}
\hline Amostra & \multicolumn{2}{|c|}{ DL } & \multicolumn{2}{c|}{ DT } \\
\hline Unidade & $\mu \mathrm{m}$ & ASTM & $\mu \mathrm{m}$ & ASTM \\
\hline Média & 2,24 & 14 & 2,22 & 14 \\
\hline Desvio Padrão & 0,24 & 0,3 & 0,09 & 0,11 \\
\hline
\end{tabular}

Podem haver diferenças entre o valor de tamanho de grão médio obtido e o valor real devido à microestrutura ser extremamente refinada e ao fato da grande dispersão de segunda fase existente, que para a metodologia utilizada (método dos interceptos) e aumento utilizado, pode promover a referida diferença, contudo, para fins de análise comparativa entre as amostras, pode-se adotar os valores.

\subsubsection{Laminada a Frio}

Na Figura 3 são apresentadas as micrografias da amostra laminada a frio na direção de laminação, após o ataque de Nital. Pode-se observar a deformação dos grãos na direção de laminação e a presença das mesmas fases, ferrita e perlita, observadas na condição laminada a quente.

(a)
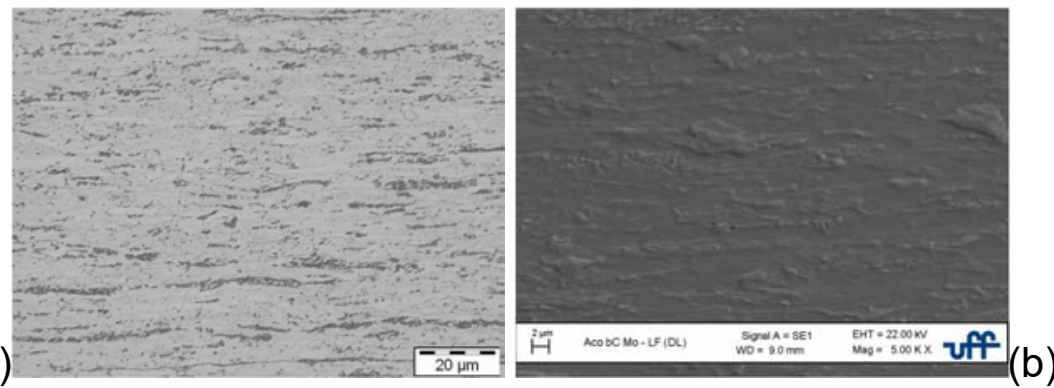

Figura 3. Amostra laminada a frio. Ataque Nital 3\% a) microscopia ótica,1000X e b) MEV com aumento de 5000X.

\subsubsection{Galvanizada}

Na Figura 4 são apresentadas as micrografias analisadas por microscopia ótica e MEV da amostra galvanizada na direção de laminação, com ataque de Nital. Verifica-se nesta condição a presença de grão ferríticos e uma segunda fase, atribuída a presença de martensita (constituinte MA - regiões em alto relevo e claras). Também pode-se observar pela análise no MEV a presença de resquícios de deformação pela presença de grãos ferríticos alongados (regiões em alto relevo de mesma coloração da de baixo relevo). 


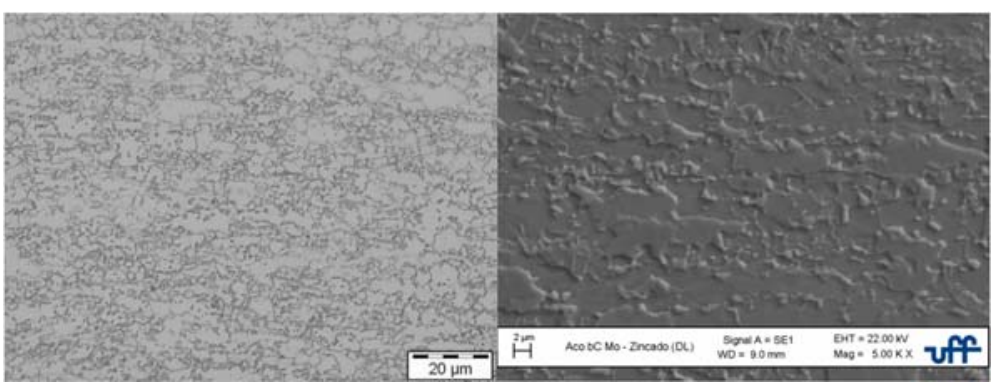

Figura 4. Micrografia amostra galvanizada DL: a) microscopia ótica,1000X e b) MEV, 5000X. Nital 3\%.

Foi realizada a quantificação de fase após o ataque de de Picral (Tabela 7).

Tabela 7. Quantificação de fase da amostra galvanizada DL. Reagente Picral.

\begin{tabular}{|c|c|c|}
\hline Fase & Constituinte MA (\%) & Carbonetos (\%) \\
\hline Média & 13,55 & 0,77 \\
\hline Desvio padrão & 2,01 & 0,45 \\
\hline
\end{tabular}

Foi possível com o uso do reagente Picral distinguir as regiões pertinentes ao constituinte MA das regiões de carbonetos.

Realizou-se também o tamanho de grãos, apresentado na Tabela 8.

Tabela 8. Determinação do tamanho de grão da amostra galvanizada DL.

\begin{tabular}{|c|c|c|}
\hline Amostra & \multicolumn{2}{|c|}{$\mathrm{DL}$} \\
\hline Unidade & $\mu \mathrm{m}$ & $\mathrm{ASTM}$ \\
\hline Média & 1,85 & 15 \\
\hline Desv Padrão & 0,12 & 0,2 \\
\hline
\end{tabular}

Podem haver diferenças entre o valor de tamanho de grão médio obtido e o valor real devido à microestrutura ser extremamente refinada e ao fato da grande dispersão de segunda fase existente, que para a metodologia utilizada (método dos interceptos) e aumento utilizad, pode promover a referida diferença, contudo, para fins de análise comparativa entre as amostras, pode-se adotar os valores.

\subsection{Ensaios mecânicos}

Os resultados referentes a dureza Vickers das amostras em estudo são apresentados no gráfico da Figura 5. Estes resultados estão coerentes com as microestruturas observadas no tópico anterior, onde a placa apresenta grãos ferríticos grosseiros com fração volumétrica acima de $80 \%$, possibilitando assim uma baixa dureza. Após a laminação a quente a dureza do material teve um acréscimo, o que pode ser explicado pelo fato de ter ocorrido um refino de grão durante a deformação na laminação a quente controlada. A maior dureza é observada no material laminado a frio, o que pode ser entendido devido ao material estar com elevado nível de encruamento. Após a galvanização o material apresenta um decréscimo de dureza, quando comparado ao LF, que está relacionado a recristalização ocorrida durante o recozimento. Porém quando se compara o material galvanizado ao $L Q$, o mesmo apresenta um valor elevado de dureza que se deve ao fato do material galvanizado apresentar ilhas dispersas de martensita (constituinte MA) que ocasionam um aumento de dureza, além da presença de pequenas regiões de ferida deformada. 
Os valores de propriedades mecânicas referentes aos ensaios de tração uniaxial das amostras retiradas após a laminação a quente e galvanização na direção diagonal, transversal e longitudinal à laminação são apresentados nas Tabelas 9 e 10.

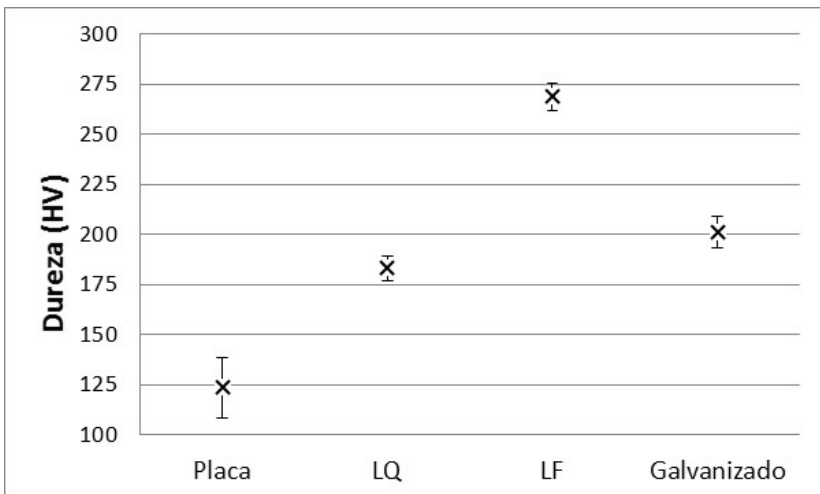

Figura 5. Gráfico dureza Vickers nas distintas etapas de produção de "Dual Phase".

Tabela 9. Propriedades mecânicas da amostra retirada após laminação a quente (direção longitudinal em relação a laminação).

\begin{tabular}{|c|c|c|c|c|c|c|}
\hline Corpo de prova & $\begin{array}{c}\text { Tensão } \\
\text { Patamar } \\
\text { superior } \\
\text { (Mpa) }\end{array}$ & $\begin{array}{c}\text { Tensão } \\
\text { Patamar } \\
\text { Inferior } \\
\text { (Mpa) }\end{array}$ & LR (MPa) & $\begin{array}{c}\text { Razão } \\
\text { Elastica } \\
\text { Superior }\end{array}$ & $\begin{array}{c}\text { Razão } \\
\text { Elastica } \\
\text { Inferior }\end{array}$ & $\begin{array}{c}\text { Alongamento } \\
\text { (\%) }\end{array}$ \\
\hline Média & 472 & 466 & 540 & 0,883 & 0,873 & 23 \\
\hline Desvio Padrão & 20 & 21 & 55 & 0,107 & 0,110 & 1 \\
\hline
\end{tabular}

Os corpos de prova LQ apresentaram patamar de escoamento típico dos aços ferrítico-perlíticos e alongamento comparados aos aços "Dual Phase" galvanizados. Os baixos valores de razão elástica apresentados pelos corpos de prova galvanizados, em geral, anunciam uma maior capacidade de encruamento do material e uma maior ductilidade, fatores esses que podem contribuir para um melhor desempenho do material em operações de conformação, além de permitir a estes aços a capacidade de absorver grande quantidade de deformação sem risco de ruptura [4]. As propriedades mecânicas obtidas a partir das amostras LQ e galvanizada estão completamente relacionados com a microestrutura, onde o refino de grão aliado a presença de ilhas de martensita dispersas na matriz ferrítica possibilitaram um aumento do limite de resistência aliado a um decréscimo do limite de escoamento, sem ocasionar perda considerável de ductilidade. Além disso, possibilitou o decréscimo da razão elástica, que como discutido no parágrafo anterior ocasiona uma melhora de conformabilidade.

Tabela 10. Propriedades mecânicas da amostra retirada após a galvanização (direção longitudinal em relação a laminação).

\begin{tabular}{|c|c|c|c|c|c|c|c|c|}
\hline $\begin{array}{c}\text { Corpo } \\
\text { de prova }\end{array}$ & $\begin{array}{c}\text { LE 0.2 \% } \\
(\mathrm{MPa})\end{array}$ & LR (MPa) & $\begin{array}{c}\text { Razão } \\
\text { Elastica }\end{array}$ & $\begin{array}{c}\text { Alongamento } \\
(\%)\end{array}$ & $\begin{array}{c}r \\
(20 \%)\end{array}$ & $\begin{array}{c}\mathrm{n}(10- \\
20 \%)\end{array}$ & $\mathrm{r}$ médio & $\Delta r$ \\
\hline Média & 402 & 609 & 0,66 & 22 & 0,613 & 0,177 & 0,904 & $-0,426$ \\
\hline $\begin{array}{c}\text { Desvio } \\
\text { Padrão }\end{array}$ & 16 & 5 & 0,03 & 0 & 0,075 & 0,005 & 0,064 & 0,107 \\
\hline
\end{tabular}




\section{CONCLUSÕES}

Com base nos resultados obtidos e discussão apresentado, conclui-se que:

As condições de deformação a quente e a frio estão sendo eficazes no refinamento de grão da microestrutura do produto final, ocasionando junto a presença de martensita a obtenção de um material com alto limite de resistência e alongamento apreciável.

O recozimento intercrítico realizado na linha de galvanização está sendo realizado em uma temperatura suficiente para proporcionar o enriquecimento da austenita, de modo a formar martensita no resfriamento sem evidências de percentuais significativos associados a presença de perlita e/ou bainita.

A taxa de resfriamento foi suficiente para proporcionar a transformação martensítica para a composição do aço analisada, aliada a temperatura de recozimento intercrítico.

\section{Agradecimentos}

Os autores agradecem à Companhia Siderúrgica Nacional (CSN) pelo fornecimento do material e recursos técnico-laboratoriais disponibilizados para a execução deste trabalho. A UFF pelos recursos para caracterização microestrutural utilizados.

\section{REFERÊNCIAS}

1 FONSECA, F.A.V. Aço bifásico Processado via Linha de Galvanização Continua Revisão e estágio atual de produção na USIMINAS/UNIGAL - Contribuição Técnica ao $42^{\circ}$ Seminário de Laminação da ABM - Processos e Produtos Laminados e Revestidos; Santos, SP, 25 a 28 de outubro de 2005.

2 RASHID, M. S. GM 980X - Potential Applications and Review. International Automotive Engineering Congress and Exposition. S.A.E. Technical Publication $\mathrm{n}^{\circ} 770211$. Detroit (EUA), fev./mar. 1977, 12 p.

3 GORNI, A.A. Efeito da Temperatura de Acabamento e Velocidade de Resfriamento sobre a Microestrutura e Propriedades Mecânicas de um Aço Bifásico. Dissertação de Mestrado, Dep. de Eng. Metalúrgica da Escola Politécnica da USP, 1989, p.184.

$4 \quad$ KUVIN, B. So much information, so little time. Metalforming magazine.V.41, N. 7, p. 4445, 2007. 